\title{
Introduction of supporting papers
}

\author{
Hallgrímur Snorrason \\ Statistics Iceland, Skuggasund 3, IS-150 Reykjavik, Iceland
}

In organising this session it was decided that there would be two types of papers, main papers from invited authors and supporting papers that might be submitted by individual countries or the international/supranational agencies. The supporting papers might deal with any aspect of our main topic. According to the agreed rules for this game, the supporting papers were not to be read out or presented by the country in question. Instead, the chairman would present them in a joint introduction summarizing their salient points.

Nine countries responded to this invitation sending in ten papers dealing in various ways with our subject matter. Of the ten papers, seven are submitted by six newly independent countries or countries in transition discussing their new realities in defining, establishing and exercising proper relations with and proper boundaries between the NSI (national statistical institute) and the government administration. On the other hand, we have three papers from three of the best anchored NSI's in our region, discussing their experience of how the relationship between the NSI and the government may de developed much beyond the basic ground rules as portrayed by the Fundamental Principles.

Let me deal first with the seven papers from the newly independent or transition countries, Armenia, Azerbaijan, Hungary (two papers), The former Yugoslav Republic of Macedonia, Slovenia and the Republic of South Africa. I include the South Africa paper in this group since it deals essentially with the transition of a government statistical service in a totalitarian state to one in a democratic state. I will first mention some common traits of the papers and then go on to account briefly for the situations, problems or tasks that seem specific to each country.

Concentrating first on similarities, the seven supporting papers from the six transition countries depict many common characteristics of development. All the NSI's concerned have been through a phase of substantial reform. This has in all instances led to the enactment of a new statistical law, very much based on or taking into account the Fundamental Principles. Here, it may be pointed out that the relevance or the impact of the Principles does not date from the formal adoption by the UN Statistical Commission in 1994 or the preceding adoption by the ECE in 1992 following the agreement reached at our Conference the year before. Their impact or the influence of a set of principles that ought to govern the organization of an NSI goes at least back to the discussions that were started 
around 1990, in particular within the Conference of European Statisticians. This is reflected in some of the supporting papers, for example those of Hungary and Slovenia.

Another common trait shown by the papers, is the insistence on confidentiality, both in legislation and in practice. This represents a clear break from previous practices in the centrally planned economies when the individual data was there for the government to use at its will. The papers before us carry a clear indication that such practices are no longer acceptable. In this connection we may perhaps speculate a little on one interesting feature partly taken up by Tim Holt in his main paper. He mentions the fact that the Fundamental Principles seem not only to have influenced legislation in transition countries but also in the well established democratic countries of Western Europe. I think that this may particularly be the case as regards confidentiality. The basic rules on confidentiality that we wrote down in the Fundamental Principles were certainly much in line with prevailing practices but these were on the other hand very variously treated in national legislation. It seems to me that this has in a few instances at least been rectified since then, partly owing to the Fundamental Principles but partly to deliberations and the strategies and regulations adopted by the European Union and the countries of the European Economic Area in the years 1989-1991. Thus, both the Fundamental Principles and the EU legislation showed up the need for formalization of confidentiality principles in national legislation.

Another factor which concerns the relationship between the NSI and government and seems similar in the transition countries reporting to our session, is the emphasis on formal statistical plans that require government or parliamentary approval. Here, of course, one may agree that the emphasis on planning is mainly the evidence of sound management policy. But judging from some of the papers it is tempting to suggest that the way in which some of the NSI's in transition countries have produced formal plans for their overall activities for formal discussion and approval of the government has been seen as an important factor of the professional independence of the offices. Having a statistical plan formally approved, stamped and sealed by the government may not only be regarded as helpful for budgetary reasons but also as one of the foundations for the autonomy of the NSI's vis-à-vis ministries, other government departments and even the government itself.

Professional independence, the freedom of the NSI to decide on purely professional grounds on the methodology, definitions, classifications and dissemination to be applied is emphasized or mentioned by all the authors. This even extends to the practice of commenting on wrong interpretation. The dissemination issue is mentioned by some of the authors conveying the satisfaction that the NSI's are now in control of their practices in that respect. A clear evidence of that is the fact that seven transition countries (Croatia, Hungary, Latvia, Lithuania, Poland, Slovenia, Czech Republic), have now fulfilled the IMF's special data dissemination standards (SDDS) and appear on the SDDS Bulletin Board on the Internet.

Turning now to the individual papers, the Armenian one accounts for the estab- 
lishment in 1990 of a professionally independent central statistical authority which now operates on the basis of a modern law from 1996. The Department of Statistics has all the main functions of a NSI. Of particular interest is the mention made of the contacts established with users concerning "the drawing up of report forms and the system of statistical indicators". Another point is the role and activity of the Scientific and Methodological Council of the Statistical Office which submits twice a month to the government analytical material on various issues of economic and social statistics. It is easy to see that if correctly established and composed, in a non-political manner, such a council may well prove to be an important vehicle for assuring both the government and the public of the neutral and professional stand of the NSI. A third point of interest on the Armenian scene is the strong status of the Department of Statistics vis-à-vis both other government departments and local authorities, a situation that some western NSI's may well be envious of.

National statistics in Azerbaijan have gone through radical reforms in the last few years. Like in Armenia this has resulted in the establishment of an independent non-political organization charged with the responsibility of carrying out the functions of a modern NSI. The organization, called the State Statistical Committee, works on the basis of statistical legislation and regulations as well as of a statistical plan which is examined yearly by the Cabinet. Apart from this, there are two points in the Azerbaijan paper that I would particularly like to mention. One is that the statistical office seems to try to cater to the needs of different kinds of users and disseminates its statistics in many forms. It is interesting to note in this connection that the NSI may provide against payment such statistical services that it is not obliged by law to produce. The other issue that I found especially interesting is the fact that in spite of a strong central status, a solid legal basis, its right of access to all information sources, and in spite of confidentiality regulations and pledges, the NSI faces serious difficulties in data collection. Respondents are not responding, or not responding regularly or they are supplying data of poor quality. This should not come as a surprise for any of us given our own expericence and bearing in mind the very fluid situation in the transition countries resulting from the abrupt and radical economic and social transformation that has taken place in this decade.

The Hungarian paper on the evaluation of the relationship between the government and the NSI very much emphasizes that not only is the correct legislation in place but that it is also carried out in practice. While I do not find some of the more legalistic arguments for this fully convincing, I agree with the authors that the full publicity of statistical data according to the statistical law is a good warrant of objectivity. A further warrant of the professional independence is the National Statistical Council. The Council seems to have tasks similar to those of its counterpart in Azerbaijan and it is composed of members representing official statistics, interest groups, local councils, and the scientific community.

The discussion on data protection in the Hungarian paper is of interest. Not least owing to previous malpractices, the Hungarian legislation on data protection is 
very strict, so strict as to be seen as hindering data collection for statistical purposes or as it is stated: "Data protection exaggerated both in theory and in practice hinders the flow of information for the time being". It is interesting to compare this situation with what is described in the other papers. None of those mention difficulties similar to the Hungarian ones, quite the contrary. In particular, the situation seems very different in The former Yugoslav Republic of Macedonia. There, all the proper formal requirements are in place and practised successfully. But it is to be understood that this is not particularly burdensome as data users and especially government organs are not accustomed to individual data as it is much simpler for their purposes to use aggregated data.

The other paper from the Hungarian CSO deals with the impact on official statistics of the use of statistical data, definitions and classifications in non-statistical areas, such as taxation, administrative registers, for benchmarking, resource allocation etc. Here, the Hungarians report that there is heavy pressure on the CSO to adjust statistical practices to administrative purposes. In the same vein, there are instances of "flexible" interpretations of statistical methods and definitions according to the interests at stake. The experience, however, is not uniformly negative as the "extra-mural" use of statistical data and methodology may render useful experience and provide feedback of value for the NSI. Finally, the Hungarian paper carries an account of the CSO successfully maintaining the control of statistical tools, presumably definitions and classifications, within the system of taxation. I will not discuss this further here except to mention that a similar theme concerning definitions and classifications appears in paper from The former Yugoslav Republic of Macedonia. There it is reported that there have been pressures by government organs to change definitions or apply old ones in order to provide different interpretation of economic policy. Furthermore, that there is a slight resistance to the introduction of new standards that have a bearing on other legislative acts or administrative provisions.

Continuing with the paper from The former Yugoslav Republic of Macedonia, it in a way tells a similar story to that accounted for previously. Like in the case of Armenia and even Azerbaijan an emphasis is placed on consultations with users concerning statistical programming as well as dissemination and timeliness. As regards the government/NSI relationship, three issues may be noted: 1) The NSI makes an effort to train governmental users in their use of statistics; 2) That new information on key indicators is given to Cabinet ministers prior to public release; up to now this has not caused complications nor delays; 3) That in the case of a wrong interpretation by a government organ, the Statistical Office will always react in a written form with appropriate comments and explanations.

In his paper on the Slovenian situation, Mr. Banovec describes how the relationship between the government and the NSI had already been correctly moulded on the Fundamental Principles prior to the present act on official statistics from 1995. Indeed, the Principles are both firmly established and practised in Slovenia. However, he points out the obvious drawback that professional freedom may not be very meaningful if that is not backed up by sufficient budgetary appropriations or 
other sources of funds for exercising that freedom and carrying out its functions. Another problem accounted for, no doubt a related one, is the technical hindrance to releasing data simultaneously to all users.

Like the papers from Hungary and The former Yugoslav Republic of Macedonia, the Slovenian paper discusses the use of statistical results, definitions and nomenclatures for administrative purposes. This is particularly sensitive in Slovenia owing to the utilization of administrative registers for statistical purposes. Cases of misuse of definitions and data often occur when statistical classifications are also used for administrative purposes. This can be very inconvenient, in particular as generalized statistical findings may differ from results based on apparently similar sources, that is to say when both are register based.

The paper from South Africa written by Orkin, Lehohla and Kahimbaara is certainly in a class of its own owing to the very specific and extreme circumstances it describes. The authors account for the state and the transformation of the government statistical services in the post apartheid years, using the population census of 1996 as a case study. The story itself is a relatively straight-forward one; the resulting picture all the more shocking. A new team of management of the Central Statistical Service that replaced the old one about 1-2 years after the general elections of 1994, found the planning of the 1996 census to be totally deficient. Similar conclusions were also reached by two outside expert reports. In particular, the census plans and preparations were found to be apartheid-ridden, that is to say to basically reflect the outgoing regime's preoccupation with the white minority and its businesses. Based on this well documented case, the authors draw their conclusions that during the apartheid period the CSS had basically been shaped to serve White South Africa and especially metropolitan business interests. The statistical system had been geographically fragmented in line with the apartheid policy with the CSS giving unduly scant attention to the African majority of the population, resident in the segregated "townships" or in rural areas.

The paper then goes on to describe how the new management team and Statistical Council that was brought in in 1995 and 1996 reacted to this situation, how new policies were shaped for the government statistical services and what measures were taken. The heavy reliance on consultations with users, mainly government departments, in rescuing the census, is of particular interest. I will not go further into the paper but emphasize that to me this paper carries a major lesson: That in a totalitarian state, government statistical services are in all likelihood an integral part of the regime. Reflecting on it, there is hardly any way in which a professionally independent NSI serving the interests of the community at large can operate or may indeed be tolerated under such a regime. This may be some food for thought for organizations and countries that are engaged in statistical development projects in non-democratic or near-totalitarian states.

Having read the South African paper, I have two thoughts or requests. One is for the authors to extend the scope of their paper; for an outsider such as myself it would be of great interest if the South African experience could be illustrated 
by further case studies or examples, not least in the field of economic statistics. The other request or wish I would like of express is that we might have a better documentation than we have now of the workings of the government statistical services of the centrally planned economics and near totalitarian states of Central and Eastern Europe before 1990. Not only is this of interest from an historical point of view but it may also throw clearer light on the problem of the government/NSI relationship in general.

I have now discussed the seven papers from the six transition countries that have supplied them. As regards the development of official statistics, the overall impression of the papers is a positive one. The countries have been working hard to reform and reorganize their NSI's along the lines preached by the Fundamental Principles and practised by the long-established NSI's of the old democratic countries of Western Europe and their counterparts in the rest of the world. This notwithstanding, it has to be borne in mind that the overall picture may be somewhat illusionary or incomplete. First, there is ample evidence that the production of good quality official statistics is still an uphill battle in good many of the transition countries. Secondly, although the government/NSI relationship may have been rectified in legislation, it is by no means clear that the relationship has been transformed in reality in all the countries concerned. In other words, practical reality may be lagging somewhat behind the nice phraseology.

The second group of supporting papers, those from the NSI's of Canada, Finland and France, deals with aspects of the subject that differ very much from those discussed by the transition countries. The common denominator of those papers is that in all three countries the basic relationship between government and the NSI is well established, of long standing, non-problematic and thus of little interest. What is of interest is how it has been possible to expand on and develop this relationship to the mutual benefit of both the government administration and official statistics, if I have understood the papers correctly. Apart from this, the papers have little in common so I will here try to point to the main thrust of each of them in turn.

The Canadian paper discusses Canadian experience of the direct use of statistics in formulae to determine administrative action - or formula use of statistics as the paper has it - and of cost recovery programmes, meaning statistical programmes conducted by the NSI but funded by other organizations, most often federal ministries. Concerning the so-called formula use, the paper outlines four examples of actual projects that Statistics Canada has been involved in. In three of these cases the use of official statistics for very specific administrative purposes involving substantial allocation of funds led to an extension of the statistical production. This took the form of the application of estimation resulting in findings that were much improved from the available statistics, enlarged samples, and increased business statistics. Besides this, the paper points to other uses of statistics for benchmarking, resource allocation and eligibility where existing statistical series are simply utilized without any direct impact on the statistical system. The main problem with this so-called formula use, the paper says, is that it may involve the 
NSI in controversies owing to discontent over and disagreement with the results. Nevertheless, the overall impact is a favourable one. The experience of cost recovery programmes is similarly a positive one; it allows the NSI to expand its activities and engage in new and/or improved undertakings. However, the paper emphasizes that this can only be allowed if certain basic conditions of ethics or good practices are fulfilled. Moreover, the project must also be relevant, appropriate, and be in some way related to the statistical programme of the NSI.

Hence, if all conditions are fulfilled and proper care taken the main conclusion of the paper is that both formula use and cost recovery programmes can be of great benefit to the system of official statistics by leading to the initiation of new programmes, expansion of existing ones, increases in samples, and methodological innovation. In this connection I would like to note three issues: 1) That it is very clear from the paper that this experience or this conclusion rests totally on a very close working relationship and cooperation between the NSI and the government agency involved; 2) That there are rules of ethics, conduct and proper practise that have to be closely watched and applied; 3) While recognising that things may be so bright and beautiful in their Canadian setting, it may be kept in mind that in the European setting there are numerous examples of problems arising from the direct use of statistics, classifications and definitions for benchmarking, eligibility and automatic allocation decisions.

The paper from Statistics Finland basically tells a success story of government/ NSI relations. Statistics Finland is the central statistical agency, partly owing to its formal status, partly as a result of its own accomplishments in asserting its role as the central and coordinating body of official statistics. To maintain and to enhance this role, Statistics Finland has placed a heavy emphasis on user relations, both with private industry and with government agencies. The latter is crucial, not specially for preserving the central role of the institute important as that may be, but owing to the remarkable and intensive use the Finns make of administrative registers for statistical purposes. Given the enormous economies derived from this, it is essential that Statistics Finland maintains closest possible relations with all register authorities as well as other agencies that depend upon the statistics produced on the basis of administrative records. Coordination of statistical classifications and definitions is also of great importance and requires a sound relationship between the NSI and government. Basically for these reasons, Statistics Finland sees the relationship with the government and individual government agencies to be of primary importance. Furthermore, this relationship has been developed successfully, resulting in both a sounder basis for coordination and the continued use of administrative data in the compilation of official statistics.

To me, one of the main virtues of the Finnish paper is that it indicates that life does not necessarily depend on formal documents. Statistics Finland is a central agency but not necessarily a centralized agency. Its abilities as a coordinating body depend as much on its own accomplishments and real stature as on its formal status. In order to achieve this, user relations, in particular government relations, are decisive.

The Finnish paper conveys a picture of action, activity, representation, even 
direct marketing, sauna meetings etc. The French paper on the other hand, conveys a feeling of less direct action and less strenuous activity but more of a tranquillity of an accepted, well functioning system with predetermined roles being acted out for the equal benefit of all concerned. The point of departure are the research activities undertaken within the official statistical system. Here, the paper proposes that in order to resolve the difficulties inherent in the situation, i.e. that the statistical object may not be handled with caution or may be exposed to radical criticism, the NSI has to enjoy strong credibility and must of necessity engage in statistical post-production studies. It strikes me that this may sound a little bit like life after death but nonetheless the author, Mr. Champsaur, does not advocate the French system as our final haven. The French system is essentially French, he says, and indeed so French that it can hardly serve as model for "the rest of the world" to utilize a handy definition from the IMF's Balance of Payment manual. I do agree with him for the simple reason that in this respect the cultural foundation is all-important. But although the particular system applied in France may not be immediately applicable in other circumstances it may still be studied with profit.

The importance of credibility of the NSI can hardly be denied. In France, this rests on four pillars: i) statistical confidentiality, provided for in law and by an executive body, ii) rules of dissemination of official statistics, iii) professional independence of the NSI, and iv) on a close involvement of users in the planning of official statistics.

The paper discusses at considerable length the issue of carrying out research or statistical studies. It is concluded that such activity is a necessity for several reasons. As regards our specific subject of the government/NSI relationship, Mr. Champsaur maintains that the researcher or analyst can act as mediator between statistics and politics by providing explanations and by helping to tailor the statistical output more closely to user needs. He also argues that "in-house" research and analytic activities are invaluable to the NSI itself. But everything internal is at the same time external, i.e. meant for publication. Therefore, there is a need to define a boundary for the territory of internal studies, forecasts etc. so as this does not infringe on the role of political decision makers. At the same time, there is a need to put NSI studies in competition with other studies; the NSI studies must be challengable and open to academic validation.

In conclusion, Mr. Champsaur argues that in the French system there is a clear separation between professional and administrative independence whereas in many other countries the administrative independence is regarded as a prerequisite for the professional one. In France, professional independence is guaranteed by a set of rules and practices, in particular imbedded in the very hierarchical system of civil service which is very peculiar to France. Hence, despite all its virtues of professionalism the overall conclusion is that the French system should not serve as models for others.

In my summary of the supporting papers I have not been able to account for or comment on all the issues raised. Furthermore, I may have missed a point or be guilty of incorrect interpretation, such is the variety of the papers and the situa- 
tions they describe. While accepting full responsibility and regretting any such mistake I would like to point out that although the supporting papers have been introduced here together they are all on the website of the ECE Statistics Division where each of them may be easily accessed (http://www.unece.org/stats).

Hallgrímur Snorrason is Director-General of Statistics Iceland 